\title{
Imagined Ugliness: Can an Orthodontist Figure it out?
}

\section{Rajlaxmi R, Kinjal M*, Abhijit M, Nilesh M and Komal T}

Department of Orthodontics, Rural Dental College, India

*Corresponding author: Kinjal Mavani, Assistant Professor, Department of Orthodontics, Rural Dental College, Loni, Maharashtra, India, E-mail: drkinjal88@gmail.com

\section{Review Article}

Volume 3 Issue 1

Received Date: February 06, 2018

Published Date: February 26, 2018

DOI: 10.23880 /oajds-16000163

\section{Abstract}

We as orthodontists' always try to give the best possible smile to our patients keeping their best interest in mind. Sometimes we might get patients who are not happy with the final results after treatment or may show excessive concern on minimal flaws \& seek orthodontic treatment. Its time like this when an orthodontist should be able to discern the issue $\&$ take a call whether to treat patients preoccupancy with his perceived defect in appearance. This article will throw some light on various literature related to BDD, the psychological effects on patients, the role of an orthodontist in such cases \& how we should proceed.

Keywords: Body Dysmorphic Disorder (BDD); Orthodontist; Aesthetics

Abbreviations: BDD: Body Dysmorphic Disorder; OCD: Obsessive-Compulsive Disorder; CBT: Cognitive Behavioral Therapy; SSRIs: Selective Serotonin Reuptake Inhibitors;

\section{Introduction}

"Beauty is in the eyes of the beholder" they say. But what if the beholder has a twisted image of themselves in their mind? Perceptions of beauty changes with culture \& time, there is no specific mathematical equation for beauty. While all beauty is not universal, the human face in particular can be shown to universally appear more "beautiful" based on geometric comparisons [1]. If the face were a song, one could think of the front view as the melody and the side view as the harmony or overtones. The frontal view of the face is the most important view because we generally perceive each other (particularly when we interact socially) from the front not from the side. Our evaluation of how another face appears occurs from the frontal view. Therefore this view is MOST critical for our evaluation of another individual. The human face conforms most closely to phi proportions when we smile. You'll be perceived as more beautiful with a warm smile than with a cold-hearted look of anger, arrogance or contempt.

Even with a perfectly proportioned face though, there are endless variations in coloring and the shapes of each facial feature (eyes, eyebrows, lips, nose, etc.) that gives rise to the distinctive appearance of each race and provide for endless variations in beauty that are as unique as each individual. Interestingly, symmetry in face does not necessarily equate to beauty. Many, if not most, faces that are perceived as beautiful are usually not even close to being perfect in symmetry of the left and right sides.

Our human brains are complex structures that are geniuses in themselves. It can give one person the ability to capture the world whereas sometimes it can lock the mind in its own cage of self doubts. We all have that one imperfection we wish we could change - a crooked tooth, a large nose, acne-prone skin, eyes that are too narrow, a flabby stomach, and the list goes on. However, we accept it and carry on with our daily lives - it's more of an 


\section{Open Access Journal of Dental Sciences}

annoyance than a debilitating thought. People suffering Body Dysmorphic Disorder (BDD), become fixated on that imperfection-in fact obsessed, until it becomes the only thing they see when they look in a mirror. These obsessive and controlling thoughts can lead them to spend exorbitant amounts of time \& money trying to cover or conceal the flaw, to seek verbal approval of their looks, even though they are not likely to believe what people tell them, to socially withdraw, and to have thoughts of suicide.

BDD is described as a distressing pre-occupation with perceived defects in appearance or excessive concern over minimal defects which cannot be better accounted for other mental disorders such as anorexia nervosa, gender identity disorder, major depressive disorder, avoidant personality disorder or social phobia. Approximately $1.7 \%$ to $2.4 \%$ of the U.S population are reportedly known to be affected, with roughly equal distribution among men and women. Though the percentile seems small it's mainly due to the fact that majority of such patients go unnoticed \& don't seek proper medical help. BDD is a poorly studied condition among Asian populations.

The disorder usually first surfaces in adolescence and is characterized not only by obsessive thinking about a flaw that is usually imagined or if present, hardly noticeable to the general population, but also characterized by compulsive checking of the perceived flaw (for example, spending lots of time in front of the mirror), engaging in behaviours to minimize the appearance of the perceived flaw and hiding the disorder from others due to fear of social stigma. In most patients the concerns about appearance focus on the head and face. As the patients lack insight to the true nature of the problem they usually seek non psychiatric and cosmetic treatments. Even to an extent of undergoing drastic cosmetic surgeries to "fix" the flaw. Most frequently requested treatments by the BDD patients are dermatological, surgical (rhinoplasty, liposuction and breast augmentation) and dental (tooth whitening, jaw surgery and orthodontic) treatments [2].

BDD has been recently added to the somatoform disorders category (DSM IV). Clinical knowledge of the disorder particularly among general practioners is not wide spread \& a dentist not having knowledge of BDD might land up in legal redress. Though there are people suffering from this disorder general awareness is still lacking. Celebrities going under the knife just to enhance their beauty, has given shelter to this disorder in the form of "trends". Plus in the race to "we can fix everything" mentality it often goes undiagnosed.

\section{BDD in Existing Literatures}

It was first described by Enrico Morselli as dysmorphophobia in 1866 [3]. Freud's famous "Wolf Man", a case of a patient's delusions about his nose, might have been a case of BDD. High profile celebrities are even known to have this disorder the most famous example of this generation being Marilyn Monroe, Michael Jackson, the one which hits close to home is actress Ileana D'Cruz. It's time to understand the monster lurking in the shadows \& address the problem as a clinician. Because of the distorted body image caused by the disorder the person tends to believe that he or she is horribly ugly or disfigured. Dentists \& orthodontists are more likely to encounter these kind of patients as the concern of such patients involve non-existent minor flaws for Eg- odd smile, shape of lips, profiles etc. Therefore it's necessary to identify such patients in order to avoid unnecessary treatment $\&$ distress to both patient \& the clinicians.

\section{Etiology}

Little is known about what causes BDD. There is some evidence for familial aggregation and genetic links with obsessive-compulsive disorder (OCD) [4]. Other links with OCD have been suggested through neuropsychologic and neuroimaging studies, although the literature is limited and inconsistent. A clear role for the serotonin system is evidenced by the specificity of therapeutic response to serotonergic antidepressants. Some patients report a family background that prioritized appearance, but there is little specificity. A study by Monzani, et al. [5] which examined the heritability of dysmorphic concerns in a large sample of twins found that $44 \%$ of the variation in liability to dysmorphic concerns was attributable to genetic factors, environmental factors and measurement error that account for the remaining variance. Some individuals recall their BDD having been precipitated by a particular incident such as teasing, but many patients do not report a precipitating event, and the reported events probably merely precipitated the overt manifestation of an underlying predisposition [6]. Abuse and neglect can also be contributing factors [7].

\section{Symptoms \& Behaviour}

In the general population it's difficult to ascertain BDD accurately, given the degree to which people tend to be ashamed of and hide their concerns. Also, self-reported and clinician-determined rates may differ; different rating scales may produce different results. At such times we as clinicians should be able to decipher the condition. In an article about BDD Abhimanyu, et al. has given a checklist to the symptoms \& behavioural patterns in BDD [8]. 


\section{Open Access Journal of Dental Sciences}

\section{Symptoms of BDD}

a) Obsessive thoughts about perceived appearance defects.

b) Major depressive disorder symptoms.

c) Delusional thoughts and beliefs related.

d) Social and family withdrawal, social phobia, loneliness and self imposed social isolation.

e) Suicidal ideation.

f) Anxiety; possible panic attacks.

g) Chronic low self-esteem.

h) Feeling self-conscious in social environments; Strong feelings of shame.

i) Avoidant personality and/or dependent personality.

j) Inability to work or an inability to focus at work due to preoccupation with appearance.

k) Decreased academic performance

l) Problems initiating and maintaining relationships.

m) Alcohol and/or drug abuse.

n) Repetitive behaviour (such as constantly (and heavily) applying make-up; regularly checking appearance in mirrors).

\section{Compulsive behaviours of BDD}

a) Compulsive mirror checking, glancing in reflective doors, windows and other reflective surfaces. Alternatively, an inability to look at one's own reflection or photographs of oneself; also, the removal of mirrors from the home.

b) Attempting to camouflage the imagined defect: for example, using cosmetic camouflage, wearing baggy clothing, maintaining specific body posture or wearing hats.

c) Use of distraction techniques: an attempt to divert attention away from the person's perceived defect, e.g. wearing extravagant clothing or excessive jewellery.

d) Excessive grooming behaviours: skin picking, combing hair, plucking eyebrows, shaving, etc.

e) Compulsive skin-touching, especially to measure or feel the perceived defect.

\section{Approaching an Orthodontist}

De Jongh, et al's studies showed that a person having BDD is 6 times more likely to consider orthodontic treatment in the near future, compared with those without BDD traits. The reasons they might visit an orthodontist may vary from-

a) Asymmetry of the chin

b) Asymmetry of the smile

c) Unesthetic smile

d) Persistent unexplained dental pain

e) Upper midface deficiency.

\section{Common location of facial defects is as follows:}
a) Hair
b) Nose
c) Skin
d) Eyes
e) Head/face
f) Lips
g) Teeth

The patient often visits an orthodontist seeking help to enhance their smile or in hopes of improving their facial profile. The problem starts when whatever minor discrepancy present is treated \& the patient is still unsatisfied. Not all patients suffering from BDD may avoid mirrors there are a few exceptions; some of them are obsessed with the way they look hence seeking approval in the mirror is important for them. These patients may often find someone else's smile better than their own \& demand to get somewhat a similar smile. Some might complain that they still feel their teeth are protruded in relation to their face \& ask the clinician for more retraction of teeth. It is in such cases where the orthodontist has to put his foot down; yes we are meant to give an aesthetic look to the patient but in a balanced proportion that would ideally suit the patients soft tissue profile \& not continue the treatment on the whims of a patient. The patient should be thoroughly explained the outcome of unnecessary treatment, should be helped to create a positive body image; if an orthodontist feels that further counselling is necessary the patient should be referred to a psychiatrist as orthodontic treatment alone won't solve the problem in such cases.

\section{The Dysmorphic Concern Questionnaire}

Piet Oosthuizen, et al. [9] conducted a study for the assessment of dysmorphic concern, and to establish correlations with clinical variables [9]. The study reported that dysmorphic concern was not significantly influenced by the patient's age, sex or diagnosis. In terms of specific psychotic symptoms, there were weak positive correlations with thought interference and persecutory ideation. However, the strongest correlations were with depressed mood, according to the Beck Depression Inventory (BDI) but not the Montgomery Asberg Depression Rating Scale; the discrepancy was largely accounted for by the 'cognitive' depressive items on the BDI. In terms of objective assessment of dysmorphic features, ratings on the Waldrop scale for minor physical anomalies showed no correlation with concern expressed by the patient. These questions are designed to screen for people with certain concerns that are often difficult or embarrassing to talk about with their 


\section{Open Access Journal of Dental Sciences}

doctor/family/friends; and often difficult to find the right help for. The following were the questions in the

questionnaire-

\begin{tabular}{|c|c|c|c|c|c|}
\hline \multicolumn{7}{|c|}{ Have you ever } \\
\hline 1 & $\begin{array}{c}\text { Been very concerned about some aspect of your } \\
\text { physical appearance }\end{array}$ & $\begin{array}{c}\text { Not at } \\
\text { all }\end{array}$ & $\begin{array}{c}\text { Same as most } \\
\text { people }\end{array}$ & $\begin{array}{c}\text { More than most } \\
\text { people }\end{array}$ & $\begin{array}{c}\text { Much more than most } \\
\text { people }\end{array}$ \\
\hline 2 & $\begin{array}{c}\text { Considered yourself misformed or mishapen in some } \\
\text { way (eg. nose/hair/skin/sexual organs/overall body } \\
\text { build) }\end{array}$ & $\begin{array}{c}\text { Not at } \\
\text { all }\end{array}$ & $\begin{array}{c}\text { Same as most } \\
\text { people }\end{array}$ & $\begin{array}{c}\text { More than most } \\
\text { people }\end{array}$ & $\begin{array}{c}\text { Much more than most } \\
\text { people }\end{array}$ \\
\hline 3 & $\begin{array}{c}\text { Considered your body to be malfunctional in some } \\
\text { way (eg. excessive body odour, flatulence, sweating })\end{array}$ & $\begin{array}{c}\text { Not at } \\
\text { all }\end{array}$ & $\begin{array}{c}\text { Same as most } \\
\text { people }\end{array}$ & $\begin{array}{c}\text { More than most } \\
\text { people }\end{array}$ & $\begin{array}{c}\text { Much more than most } \\
\text { people }\end{array}$ \\
\hline 4 & $\begin{array}{c}\text { Consulted or felt you needed to consult a plastic } \\
\text { surgeon/dermatologist/physiscian about these } \\
\text { concerns }\end{array}$ & $\begin{array}{c}\text { Not at } \\
\text { all }\end{array}$ & $\begin{array}{c}\text { Same as most } \\
\text { people }\end{array}$ & $\begin{array}{c}\text { More than most } \\
\text { people }\end{array}$ & $\begin{array}{c}\text { Much more than most } \\
\text { people }\end{array}$ \\
\hline 5 & $\begin{array}{c}\text { Been told by others/doctor that you are normal in } \\
\text { spite of you strongly believing that something is } \\
\text { wrong with your appearance or bodily functioning }\end{array}$ & $\begin{array}{c}\text { Not at } \\
\text { all }\end{array}$ & $\begin{array}{c}\text { Same as most } \\
\text { people }\end{array}$ & $\begin{array}{c}\text { More than most } \\
\text { people }\end{array}$ & $\begin{array}{c}\text { Much more than most } \\
\text { people }\end{array}$ \\
\hline 6 & $\begin{array}{c}\text { Spent a lot of time worrying about a defect in your } \\
\text { appearance/bodily functioning }\end{array}$ & $\begin{array}{c}\text { Not at } \\
\text { all }\end{array}$ & $\begin{array}{c}\text { Same as most } \\
\text { people }\end{array}$ & $\begin{array}{c}\text { More than most } \\
\text { people }\end{array}$ & $\begin{array}{c}\text { Much more than most } \\
\text { people }\end{array}$ \\
\hline 7 & $\begin{array}{c}\text { Spent a lot of time covering up defects in your } \\
\text { appearance/bodily functioning }\end{array}$ & $\begin{array}{c}\text { Not at } \\
\text { all }\end{array}$ & $\begin{array}{c}\text { Same as most } \\
\text { people }\end{array}$ & $\begin{array}{c}\text { More than most } \\
\text { people }\end{array}$ & $\begin{array}{c}\text { Much more than most } \\
\text { people }\end{array}$ \\
\hline
\end{tabular}

Table 1: Piet Oosthuizen's Dysmorphic Concerns Questionnaire.

\section{Treatment of Body Dysmorphic Disorder}

The two most common treatment options for body dysmorphic disorder is medication and therapy. Cognitive behavioural therapy has been found to be the most effective at treating BDD and a certain type of antidepressants have also been shown to help individuals coping with the disorder.

\section{Cognitive behavioural Therapy (CBT)}

Cognitive behavioural therapy is a coping technique that teaches individuals suffering from body dysmorphia how to recognize irrational thoughts and change negative thinking patterns. Patients are instructed on how to take those negative thoughts and replace them with positive ones. Exposure and response prevention are two key processes involved in cognitive-behavioural therapy. Exposure helps individuals experiencing BDD confront situations that cause irrational fear (e.g., going out in public with the perceived flaw uncovered). Response prevention teaches you how to resist the urge to cover up your perceived flaw with makeup or clothing, how to stop seeking reassurance from others about your appearance, and how to decrease time spent repeatedly checking your appearance [10].

\section{CBT \& Antidepressants}

A causative factor's of BDD is believed to be low levels of serotonin in the brain. Antidepressants, more specifically, selective serotonin reuptake inhibitors (SSRIs) can be prescribed to individuals living with body dysmorphic disorder as they help relieve the obsessive and compulsive thoughts and behaviours associated with the disorder. The doctor may prescribe a gradual dose of antidepressants to make sure the patient tolerates the medication and the potential side effects. In some situations, an antipsychotic drug in addition to an antidepressant may also be prescribed, especially if the patient is experiencing delusions related to BDD.

\section{Surgery}

It's the last option to be considered though the surgical correction still remains controversial in such patients. But it is generally approved that surgery rarely improves the situation \& can make matters even worse because the patient finds a new defect or becomes more concerned with the existing defect. Andreasen \& Bardach [11], suggested that because the imagined defect is emotional rather than physical, the patient will rarely be satisfied with surgery. In the study of Phillips \& Diaz [12], 109 of 131 patients who had BDD had received surgical, dermatologic, or other nonpsychiatric treatments, resulting in a worsening or at best no change in BDD symptoms in $83 \%$. 


\section{Open Access Journal of Dental Sciences}

\section{Prognosis}

Many individuals with experience of Body Dysmorphic Disorder have repeatedly sought treatment from dermatologists or cosmetic surgeons with little satisfaction, before finally accepting psychiatric or psychological help. Treatment can improve the outcome of the condition for most people. Some people living with Body Dysmorphic Disorder may function reasonably well for a time and then relapse. Others may remain chronically unwell. Research on outcome without therapy is not known, but it is thought that the symptoms persist for many years.

\section{Conclusion}

BDD is a psychiatric disorder in which an individual has a pre-occupation with a 'slight' or 'perceived' defect in appearance. An orthodontist needs to be vary about individuals seeking procedures for perceived defects that are not objectively evident. Other warning signs include an excessive amount of distress and disability associated with the perceived defect and unrealistic expectations for outcome either in cosmetic or psychosocial terms. Individuals who have such risk factors should be engaged in a discussion about their problem in broad terms such as "distress" and "disability," and they should be referred to a suitable mental health professional. It won't be a shock if such individuals go doctor shopping, as they are frequently known to go from one clinician to other until they find someone who is willing to operate on them. Sometimes they seek inappropriate or unnecessary treatment from multiple health care providers including orthodontist, and are frequently dissatisfied with the results of treatment. This could potentially increase the risk of medico-legal cases for the clinician.

BDD remains an understudied psychiatric disorder. Further research is required to establish its etiopathology and neurocognitive underpinnings. Its relationship to other psychiatric disorders requires clarification. It might not be feasible to psychologically evaluate every patient but few chosen questions can be able to help identify patients who might cause problems.

\section{References}

1. Rossetti A, De Menezes, Rosati R, Ferrario VF, Sforza C (2013) The role of the golden proportion in the evaluation of facial esthetics. Angle Orthod 83(5): 801-808.

2. Yassaei S, Goldani Moghadam M, Aghili H, Tabatabaei SM (2014) Body Dysmorphic Disorder in Iranian Orthodontic Patients. Acta Med Iran 52(6): 454-457.

3. Fava GA (1992) Morelli's legacy: dysmorphophobia. Psychother Psychosom 58: 117-118.

4. Pope HG, Phillips KA, Olivardia R (2000) The Adonis complex: the secret crisis of male body obsession New York: The Free Press.

5. Monzani B, Rijsdijk F, Anson M, Iervolino AC, Cherkas L, et al. (2012) A twin study of body dysmorphic concerns. Psychol Med 42(9): 1949-1955.

6. David J Castle, Susan R, Michael K (2006) Body Dysmorphic Disorder Psychiatr Clin N Am 29(2): 521538.

7. Neziroglu F, Khemlani Patel S, Yaryura Tobias JA (2006) Rates of abuse in body dysmorphic disorder and obsessive compulsive disorder. Body Image 3(2): 189-193.

8. Ankita J, Ragni T, Kamlesh S, Pratik C, Abhimanyu R (2016) Body Dysmorphic Disorder (BDD) and the Orthodontist. Indian Journal of Orthodontics and Dentofacial Research 2(4): 142-144.

9. Oosthuizen P, Lambert T, Castle DJ (1998) Dysmorphic concern: prevalence and associations with clinical variables. Aust N Z J Psychiatry 32(1): 129-132.

10. Rosen JC, Reiter J, Orosan P (1995) Cognitivebehavioural body image therapy for body dysmorphic disorder. J Consult Clin Psychol 63(2): 263-269.

11. Andreasen NC, Bardach J (1977) Dysmorphophobia: symptoms or disease? Am J Psychiatry 134(6): 673676.

12. Phillips KA, Diaz S (1997) Gender differences in body dysmorphic disorder. J Nerv Ment Dis 185(9): 570577. 